\title{
A Musculoskeletal model for the lumbar spine
}

\author{
Miguel Christophy • Nur Adila Faruk Senan • \\ Jeffrey C. Lotz • Oliver M. O'Reilly
}

Received: 3 November 2010 / Accepted: 20 January 2011 / Published online: 12 February 2011

(c) The Author(s) 2011. This article is published with open access at Springerlink.com

\begin{abstract}
A new musculoskeletal model for the lumbar spine is described in this paper. This model features a rigid pelvis and sacrum, the five lumbar vertebrae, and a rigid torso consisting of a lumped thoracic spine and ribcage. The motion of the individual lumbar vertebrae was defined as a fraction of the net lumbar movement about the three rotational degrees of freedom: flexion-extension lateral bending, and axial rotation. Additionally, the eight main muscle groups of the lumbar spine were incorporated using 238 muscle fascicles with prescriptions for the parameters in the Hill-type muscle models obtained with the help of an extensive literature survey. The features of the model include the abilities to predict joint reactions, muscle forces, and muscle activation patterns. To illustrate the capabilities of the model and validate its physiological similarity, the model's predictions for the moment arms of the muscles are shown for a range of flexion-extension motions of the lower back. The model uses the OpenSim platform and is freely available on https://www.simtk.org/home/lumbarspine to other spinal researchers interested in analyzing the kinematics of the spine. The model can also be integrated with existing OpenSim models to build more comprehensive models of the human body.
\end{abstract}

M. Christophy · N. A. Faruk Senan · O. M. O’Reilly ( $\varangle)$

Department of Mechanical Engineering, University of California

at Berkeley, Berkeley, CA 94720-1740, USA

e-mail: oreilly@berkeley.edu

M. Christophy

e-mail: christophy@berkeley.edu

N. A. Faruk Senan

e-mail: adilafaruk@berkeley.edu

J. C. Lotz

Department of Orthopaedic Surgery, University of California

at San Francisco, San Francisco, CA 94143-0514, USA

e-mail: lotzj@orthosurg.ucsf.edu
Keywords Spinal kinematics - Musculoskeletal model · Hill-type model $\cdot$ Muscle architecture

\section{Introduction}

Lower back pain has been posited to originate from biomechanical-based deficits (Adams 2004; McGill et al. 2000; White and Panjabi 1978b). For this reason, musculoskeletal models are of great interest to back pain researchers as they provide an inexpensive and efficient method to determine features such as muscle activation patterns, joint torques and forces, contributions of passive and active stiffness elements, and optimal posture, among others, which can be used to differentiate the motion of subjects with and without lower back pain.

The complexities of the muscle architecture for the spine and interpatient variability in the spine and vertebral joint geometries, among others, naturally cause the development of these models to be both time-consuming and difficult. Despite these challenges, several models of the human lumbar spine have been presented in the literature (Bogduk et al. 1992a; Cholewicki et al. 1995; de Zee et al. 2007; El-Rich et al. 2004; Huynh et al. 2010; Lambrecht et al. 2009; McGill and Norman 1987; Shirazi-Adl 1991; Stokes and GardnerMorse 1995). Chronologically, these models typically show increased complexity and realism. The model presented in the present paper extends this body of work in two manners. First, the detailed lumbar muscle anatomy is combined with the musculotendon force-generating parameters elaborated on extensively in Zajac (1989). Second, the model is based on the open-source platform OpenSim (Delp et al. 2007) and can be incorporated into existing musculoskeletal models that have been developed using this platform. 
These models include representations of the cervical spine (Vasavada et al. 1998) and the lower limbs (Arnold et al. 2010).

The model discussed in this paper is closest in similarity to that discussed in de Zee et al. (2007). Their model, featuring the 154 muscle fascicles reviewed in Hansen et al. (2006) study, uses the commercial software Anybody. Our model incorporates a more detailed characterization of the quadratus lumborum by Phillips et al. (2008), newer data on the multifidus muscle groups, and non-zero lumbar masses and moments of inertia of the lumbar vertebral bodies for more accurate kinematic and dynamic analyses of lumbar motion. In Sect. 2.2, we review the Hill-type muscle model (Hill 1938; Zajac 1989) used in the OpenSim platform for the purposes of producing more realistic muscle activation patterns. Next, we provide a brief background on joint kinematics in Sect. 3.

Following a presentation of the model and its muscle architecture in Sect. 4, we use the model to predict the moment arms about $\mathcal{L}_{5} / \mathcal{S}_{1}$ for a range of flexion-extension motions of the lower back. The limitations of the model and proposed future refinements are subsequently discussed in Sect. 5.

\section{A review of the lumbar spine muscle architecture}

\subsection{Muscle anatomy}

The model features the eight main muscle groups of the lower back: erector spinae (ES), rectus abdominis (RA), internal obliques (IO), external obliques (EO), psoas major (PM), quadratus lumborum (QL), multifidus (MF), and the latissimus dorsi (LD). The psoas, multifidus, and quadratus lumborum muscle groups are hypothesized to act as stabilizers of the lumbar spine (Nachemson 1966, 1968; Macintosh and Bogduk 1986, 1987; McGill et al. 1996a,b, 1999; Lonnemann et al. 2008; Rosatelli et al. 2008; Ward et al. 2009a,c), while the erector spinae and the abdominal muscles (specifically, the rectus abdominis) are the primary locomotors of the spine. In the following sections, we provide a brief description of the eight different muscle groups included in the model and present the actual muscle architecture details in Table 1.

The erector spinae is the broadest and largest muscle group in the lower back. Following the description by Bogduk (2005), this muscle group has been divided into four main components: the longissimus thoracis pars lumborum (LTpL), the longissimus thoracis pars thoracis (LTpT), the iliocostalis lumborum pars thoracis (ILpT), and the iliocostalis lumborum pars lumborum (ILpL). The incorporation of these muscle groups into the model are depicted in Fig. 1. The reader is invited to cross-reference these images with
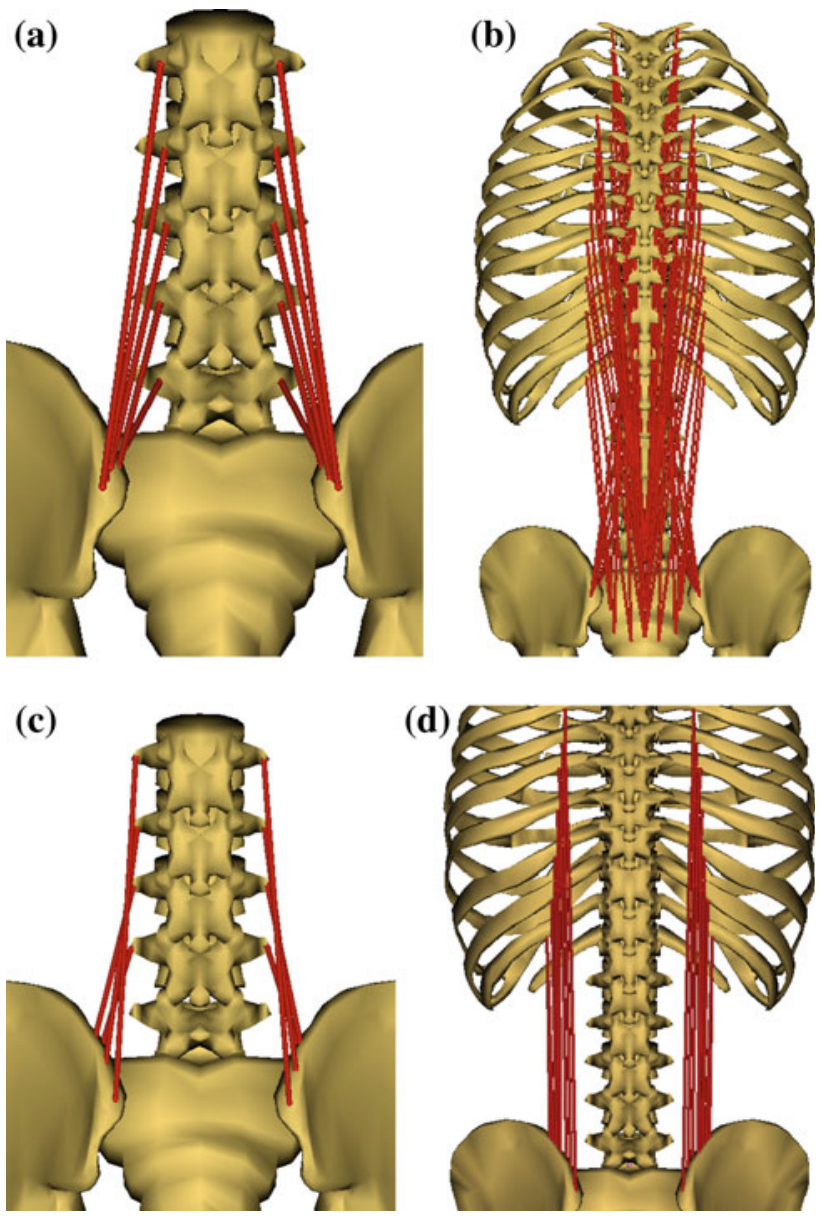

Fig. 1 The muscle architecture implemented in the model for the erector spinae muscle group: a Longissimus thoracis pars lumborum, b Longissimus thoracis pars thoracis, c Iliocostalis lumborum pars lumborum, and $\mathbf{d}$ Iliocostalis lumborum pars thoracis

those presented in the study by Macintosh and Bogduk (1987, 1991), and Bogduk et al. (1992a).

The abdominal muscles are global muscles that function primarily as flexors and axial rotators of the trunk. Our model of the internal and external obliques is based on the detailed description of these two muscle groups given in Stokes and Gardner-Morse (1999), where the obliques are each modeled using six fascicles while the explanations of Stokes and Gardner-Morse (1999) and Wilkenfeld et al. (2006) are utilized to model the rectus abdominis (see Fig. 1a).

The inclusion of the psoas major into the model follows the detailed descriptions by Bogduk et al. (1992a,b), and Santaguida and McGill (1995), and is depicted in Fig. 2b, while the attachment points of the multifidus muscle group (based on Figs. 2 and 3 of Macintosh and Bogduk 1986) are shown in Fig. 2c.

We adopted the description of the quadratus lumborum in Phillips et al. (2008) and categorized this muscle group into three subgroups: the anterior fibers, the middle 
(a)
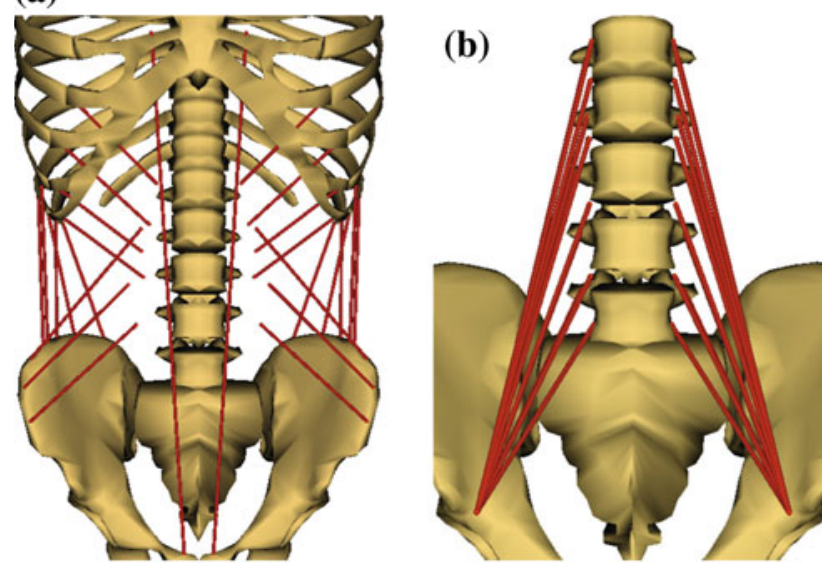

(c)

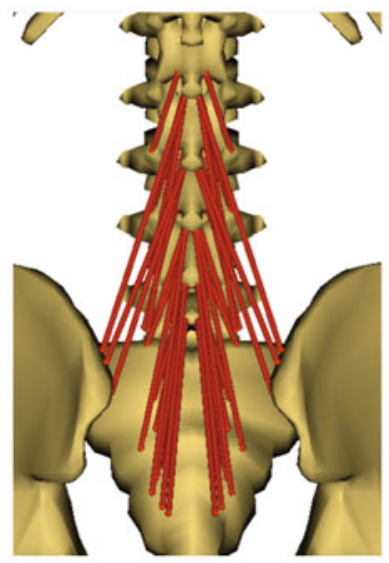

(d)

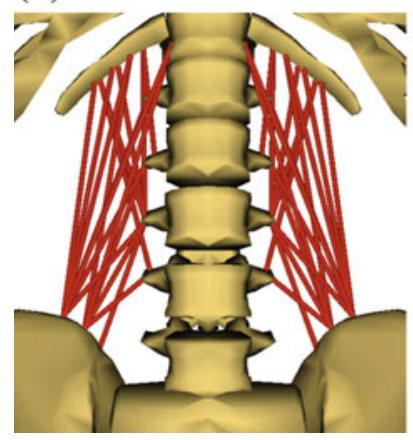

(e)

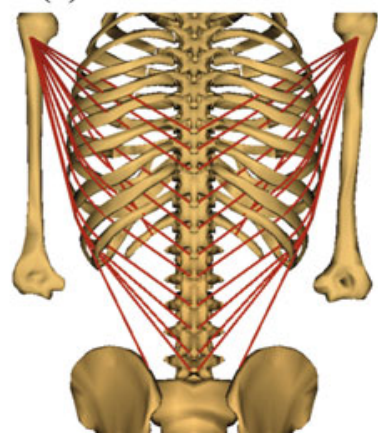

Fig. 2 The muscle architecture implemented in the model for the a Abdominals, b Psoas major, c Multifidus, d Quadratus lumborum, and e Latissimus dorsi

fibers (lumbocostals), and the posterior fibers (see Fig. 2d). However, as their anatomical study found a prevailing inconsistency in the existence of certain muscle fascicles across subjects, our model only includes muscle fascicles that were present in at least $50 \%$ of their subjects.

The attachment points for the latissimus dorsi muscle fascicles in our model were based on the comprehensive architectural study undertaken by Bogduk et al. (1998). Figure 3 of Bogduk et al. (1998) illustrates the thirteen fascicles on each side: five from the tips of the lumbar spinous processes, six from the lower six thoracic spinous processes, and costal fibers from the 11th and 12th ribs, which have been replicated in our model (Fig. 2e).

\subsection{Musculotendon models}

The musculotendon system can be approximated as a forcegenerating spring and damper system and can be described in a number of ways. One of the more commonly used is the Hill-type model (Hill 1938; Zajac 1989) utilized in the OpenSim software package to estimate muscle and tendon forces.

Briefly, the Hill-type model is composed of one non-linear spring (representing the tendon) attached to an active contractile element in parallel with a passive elastic spring. Anatomically, a pennation angle $\alpha$ is sometimes seen between the muscle and tendon (see Fig. 3a). For the purposes of modeling, it is usual to prescribe force-length and forcevelocity curves for the muscle. Typical normalized forcelength curves can be seen in Fig. 3b, c. These curves have several scaling factors, namely the maximum isometric force $\left(F_{o}^{M}\right)$, optimal fiber length $\left(\ell_{o}^{M}\right)$, and tendon slack length $\left(\ell_{s}^{T}\right)$. Each of these factors must be chosen appropriately in order to obtain physiologically meaningful results.

The lumbar spine model we developed here employs the musculotendon model described in Thelen (2003). This model is an improvement over the basic Hill-type model as it allows for the incorporation of age-related changes in dynamic contraction. However, as our efforts in this paper are directed more towards the development of the model and less toward the estimation of muscle forces and joint moments due to a given motion or load, we refer the interested reader to the Appendix section of Thelen (2003) for a more thorough explanation of the parameters necessary to compute the ensuing muscle forces. These include the passive muscle and tendon strain due to the maximum isometric muscle force $F_{o}^{M}$, the active and passive shape factors, the force-velocity shape factor, and the maximum normalized lengthening force. Changing these parameters affect the force exerted by the muscles in different ways and would be an interesting avenue of further study.

\subsection{Determination of muscle parameters}

Even with Zajac and Hill's notable work on producing a simplified mathematical model of the musculotendon actuators, one is still left with the task of determining the necessary parameters $\left(F_{o}^{M}, \ell_{o}^{M}, \alpha\right.$, and $\left.\ell_{s}^{T}\right)$. Unfortunately, these parameters are non-trivial to estimate and prescribing their values involves detailed anatomical studies, assumptions, and estimation algorithms (Garner and Pandy 2003).

Physiological cross-sectional area (PCSA) is commonly scaled as a good approximation to maximum isometric force 
Fig. 3 A Hill-type muscle model used to represent the force-generating capacity of a musculotendon actuator. Here, $F^{M}$ is the muscle force, $F^{T}$ is the tendon force, $\alpha$ is the muscle fiber pennation angle, $\ell^{T}$ is the tendon length, $\ell^{M}$ is the muscle fiber length, $\ell^{M T}$ is the length of the musculotendon actuator, $a$ is the muscle activation level, $k^{P E}$ is the passive shape factor, and $k^{T}$ is the tendon stiffness. a The mechanical model. b A normalized muscle force-length curve. c A normalized force-length curve based on the modifications made by Thelen (2003). The images are reproduced from a, b Delp et al. (1990), and c Thelen (2003)
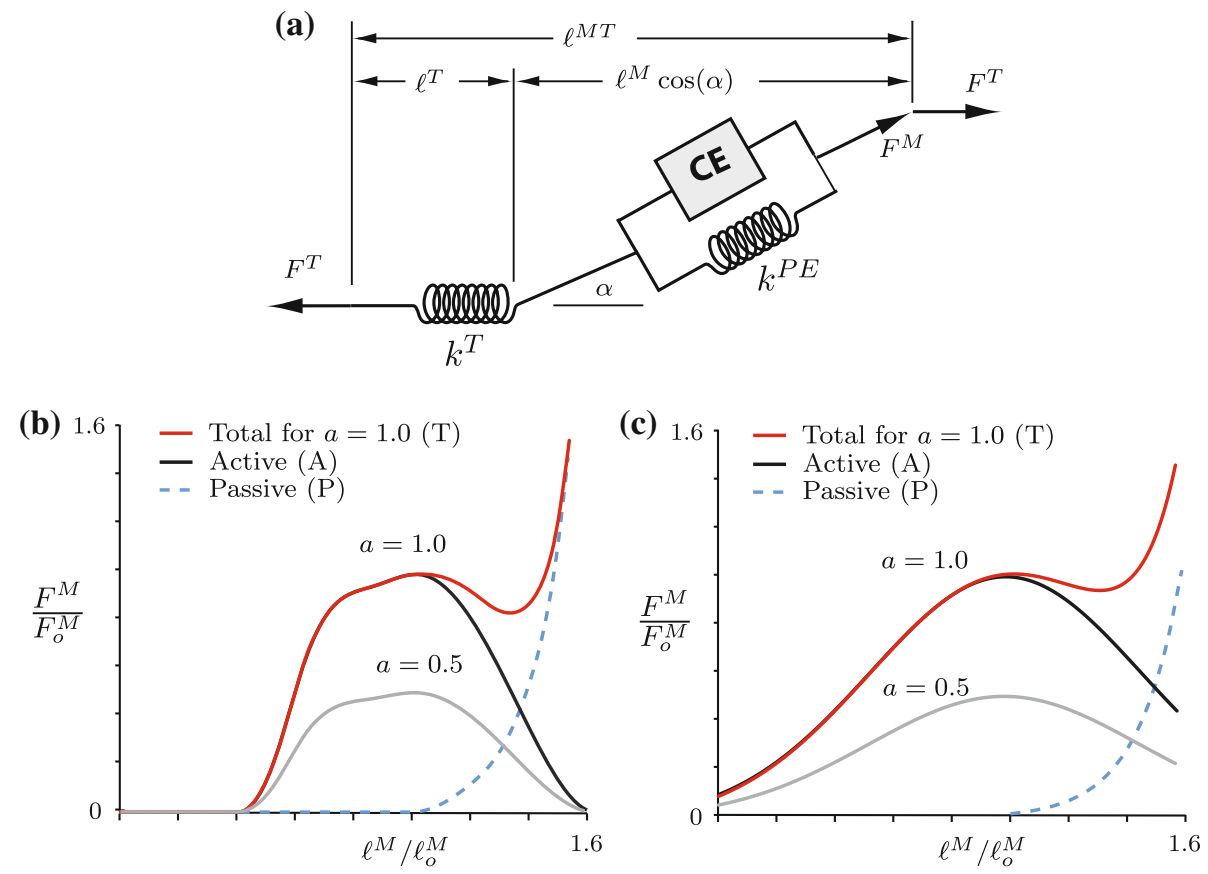

$F_{o}^{M}$. In their extensive anatomical studies of the spine, Bogduk (1980, 2005); Bogduk et al. (1992a) and Macintosh and Bogduk $(1987,1991)$ determine PCSA by dividing muscle volume by muscle fascicle length:

$P C S A=\frac{V o l_{\mathrm{mf}}}{\ell_{\mathrm{mf}}}$.

Others such as Han et al. (1992) and Hultman et al. (1993) use a series of computed tomography scans to produce an estimate of the PCSA.

Due to different methods and varying subject ages, reported values of PCSA for the lumbar musculature are inconsistent. In addition, some anatomical studies only focused on particular muscle groups, while ignoring others. Therefore, data for the lumbar musculature were gathered from several sources (Bogduk et al. 1992a; Delp et al. 2001; Phillips et al. 2008; Rosatelli et al. 2008; Stokes and Gardner-Morse 1999), as opposed to a cohesive set of subjects. Piecing together data from several dissection studies is not ideal (Arnold et al. 2010). Hence, in order to increase accuracy and consistency, the data for muscle groups were normalized against the erector spinae and compared with the data presented by Marras et al. (2001). Our motivation for using the ES muscle group to normalize the other muscle groups was driven by the fact that it was both the largest muscle group and that there were more data on this muscle group than any of the others.

Table 2 gives a summary of a comparison of PCSA for the muscle groups, where the data presented by our model is summed over all the fascicles within that group.
The relationship which scales PCSA to maximum isometric force is

$F_{o}^{M}=K \times$ PCSA

However, the estimation of the force coefficient $K$, commonly referred to as the specific tension, has reported values ranging from 34 to $100 \mathrm{~N} / \mathrm{cm}^{2}$ (Farfan 1973; Weis-Fogh and Alexander 1977; Bogduk et al. 1992a; El-Rich et al. 2004; Arnold et al. 2010; Ikai and Fukunaga 1968; van Dieèn and Kingma 1999; Schultz and Andersson 1981). Recent models (Vasavada et al. 1998; Hansen et al. 2006; Arnold et al. 2010) have utilized values of $K$ in the range of $35-61 \mathrm{~N} / \mathrm{cm}^{2}$. In the interest of consistency with our extensive use of Bogduk and Macintosh's muscle data, a $K$ value of $46 \mathrm{~N} / \mathrm{cm}^{2}$ was employed.

We utilized the pennation angles of the ES, QL, and RA as reported in Delp et al. (2001) for our model under the assumption that the pennation angle for a muscle group is fairly consistent among all fascicles in that group. Pennation data for the psoas were obtained from the detailed descriptions by Ward et al. (2009a) and Arnold et al. (2010). The pennation angle of the lumbar MF was assumed to be zero based on a study of the cervical MF by Anderson et al. (2005) and descriptions of the muscle geometry in Macintosh and Bogduk (1986); Rosatelli et al. (2008) and Ward et al. (2009c,b). Likewise, the pennation angle for the LD was also taken to be negligible as a consequence of insufficient information.

Muscle fiber length was determined based on a ratio of musculotendon length: $\ell^{f} / \ell^{M T}$ (see Table 1). Optimal fiber length $\left(\ell_{o}^{M}\right)$ is assumed to scale with optimal sarcomere 
Table 1 Muscle modeling parameters: PCSA $\left(\mathrm{mm}^{2}\right)$, maximum isometric force $F_{o}^{M}(\mathrm{~N})$, a ratio of the muscle fiber length to the musculotendon length $\ell^{f} / \ell^{M T}$, sarcomere length $\ell^{S}(\mu \mathrm{m})$, optimal fiber length $\ell_{o}^{M}(\mathrm{~m})$, pennation angle $\alpha$ (degrees), and tendon slack length $\ell_{S}^{T}$ (m)

\begin{tabular}{|c|c|c|c|c|c|c|c|c|}
\hline Muscle & Name & PCSA & $F_{o}^{M}$ & $\ell^{f} / \ell^{M T}$ & $\ell^{S}$ & $\ell_{o}^{M}$ & $\alpha$ & $\ell_{S}^{T}$ \\
\hline \multirow[t]{12}{*}{ Psoas } & & [B-Ps] & est. & {$[\mathrm{G}]$} & {$[\mathrm{W}]$} & & {$[\mathrm{Ar}]$} & \\
\hline & Ps_L1_VB & 211 & 97 & 0.800 & 3.11 & 0.1841 & 10.7 & 0.0647 \\
\hline & Ps_L1_TP & 61 & 28 & 0.800 & 3.11 & 0.1818 & 10.7 & 0.0639 \\
\hline & Ps_L2_TP & 211 & 97 & 0.800 & 3.11 & 0.1597 & 10.7 & 0.0561 \\
\hline & Ps_L3_TP & 101 & 46 & 0.800 & 3.11 & 0.1394 & 10.7 & 0.0490 \\
\hline & Ps_L4_TP & 161 & 74 & 0.800 & 3.11 & 0.1195 & 10.7 & 0.0420 \\
\hline & Ps_L5_TP & 173 & 80 & 0.800 & 3.11 & 0.1034 & 10.7 & 0.0363 \\
\hline & Ps_L5_VB & 191 & 88 & 0.800 & 3.11 & 0.0903 & 10.7 & 0.0317 \\
\hline & Ps_L1_L2_IVD & 120 & 55 & 0.800 & 3.11 & 0.1660 & 10.7 & 0.0583 \\
\hline & Ps_L2_L3_IVD & 119 & 55 & 0.800 & 3.11 & 0.1440 & 10.7 & 0.0506 \\
\hline & Ps_L3_L4_IVD & 36 & 17 & 0.800 & 3.11 & 0.1235 & 10.7 & 0.0434 \\
\hline & Ps_L4_L5_IVD & 79 & 36 & 0.800 & 3.11 & 0.0998 & 10.7 & 0.0351 \\
\hline \multirow[t]{2}{*}{ RA } & & {$[\mathrm{S}]$} & & [D] & [D] & & [D] & \\
\hline & rect_abd & 567 & 261 & 0.788 & 2.83 & 0.2986 & 0 & 0.0810 \\
\hline ES & & {$[\mathrm{B} 1]$} & & {$[\mathrm{D}],[\mathrm{M}]$} & [D] & & [D] & \\
\hline \multirow[t]{4}{*}{$\mathrm{ILpL}^{b}$} & IL_L4 & 189 & 87 & 0.274 & 2.37 & 0.0167 & 13.8 & 0.0354 \\
\hline & IL_L3 & 182 & 84 & 0.274 & 2.37 & 0.0252 & 13.8 & 0.0533 \\
\hline & IL_L2 & 154 & 71 & 0.274 & 2.37 & 0.0373 & 13.8 & 0.0789 \\
\hline & IL_L1 & 108 & 50 & 0.274 & 2.37 & 0.0514 & 13.8 & 0.1089 \\
\hline \multirow[t]{8}{*}{$\operatorname{ILpT}^{a}$} & IL_R5 & 23 & 11 & 0.381 & 2.37 & 0.1546 & 13.8 & 0.2165 \\
\hline & IL_R6 & 31 & 14 & 0.417 & 2.37 & 0.1483 & 13.8 & 0.1793 \\
\hline & IL_R7 & 39 & 18 & 0.452 & 2.37 & 0.1459 & 13.8 & 0.1536 \\
\hline & IL_R8 & 34 & 16 & 0.462 & 2.37 & 0.1293 & 13.8 & 0.1308 \\
\hline & IL_R9 & 50 & 23 & 0.600 & 2.37 & 0.1424 & 13.8 & 0.0838 \\
\hline & IL_R10 & 100 & 46 & 0.600 & 2.37 & 0.1175 & 13.8 & 0.0692 \\
\hline & IL_R11 & 123 & 57 & 0.640 & 2.37 & 0.1011 & 13.8 & 0.0506 \\
\hline & IL_R12 & 147 & 68 & 0.640 & 2.37 & 0.0731 & 13.8 & 0.0366 \\
\hline \multirow[t]{17}{*}{$\mathrm{LTpT}^{a}$} & LTpT_T1 & 29 & 13 & 0.260 & 2.31 & 0.1028 & 12.6 & 0.2430 \\
\hline & LTpT_T2 & 57 & 26 & 0.257 & 2.31 & 0.1061 & 12.6 & 0.2550 \\
\hline & LTpT_T3 & 56 & 26 & 0.257 & 2.31 & 0.1067 & 12.6 & 0.2565 \\
\hline & LTpT_T4 & 23 & 10 & 0.257 & 2.31 & 0.1068 & 12.6 & 0.2566 \\
\hline & LTpT_T5 & 22 & 10 & 0.257 & 2.31 & 0.1008 & 12.6 & 0.2421 \\
\hline & LTpT_T6 & 32 & 15 & 0.267 & 2.31 & 0.1031 & 12.6 & 0.2360 \\
\hline & LTpT_T7 & 39 & 18 & 0.306 & 2.31 & 0.1183 & 12.6 & 0.2236 \\
\hline & LTpT_T8 & 63 & 29 & 0.346 & 2.31 & 0.1261 & 12.6 & 0.1997 \\
\hline & LTpT_T9 & 73 & 34 & 0.330 & 2.31 & 0.1244 & 12.6 & 0.2108 \\
\hline & LTpT_T10 & 80 & 37 & 0.330 & 2.31 & 0.1123 & 12.6 & 0.1716 \\
\hline & LTpT_T11 & 84 & 38 & 0.330 & 2.31 & 0.0980 & 12.6 & 0.1494 \\
\hline & LTpT_T12 & 69 & 32 & 0.330 & 2.31 & 0.0780 & 12.6 & 0.1189 \\
\hline & LTpT_R4 & 23 & 10 & 0.330 & 2.31 & 0.1355 & 12.6 & 0.2065 \\
\hline & LTpT_R5 & 22 & 10 & 0.330 & 2.31 & 0.1270 & 12.6 & 0.1936 \\
\hline & LTpT_R6 & 32 & 15 & 0.353 & 2.31 & 0.1357 & 12.6 & 0.1847 \\
\hline & LTpT_R7 & 39 & 18 & 0.333 & 2.31 & 0.1295 & 12.6 & 0.1942 \\
\hline & LTpT_R8 & 63 & 29 & 0.290 & 2.31 & 0.1061 & 12.6 & 0.1984 \\
\hline
\end{tabular}


Table 1 Continued

\begin{tabular}{|c|c|c|c|c|c|c|c|c|}
\hline Muscle & Name & PCSA & $F_{o}^{M}$ & $\ell^{f} / \ell^{M T}$ & $\ell^{S}$ & $\ell_{o}^{M}$ & $\alpha$ & $\ell_{S}^{T}$ \\
\hline & LTpT_R9 & 73 & 34 & 0.254 & 2.31 & 0.0915 & 12.6 & 0.2080 \\
\hline & LTpT_R10 & 80 & 37 & 0.327 & 2.31 & 0.1072 & 12.6 & 0.1657 \\
\hline & LTpT_R11 & 84 & 38 & 0.370 & 2.31 & 0.1045 & 12.6 & 0.1313 \\
\hline & LTpT_R12 & 69 & 32 & 0.300 & 2.31 & 0.0633 & 12.6 & $(0.073)^{\mathrm{c}} 0.1230$ \\
\hline \multirow[t]{5}{*}{$\mathrm{LTpL}^{a}$} & LTpL_L1 & 79 & 36 & 0.419 & 2.31 & 0.0813 & 12.6 & 0.0944 \\
\hline & LTpL_L2 & 91 & 42 & 0.433 & 2.31 & 0.0677 & 12.6 & 0.0744 \\
\hline & LTpL_L3 & 103 & 47 & 0.436 & 2.31 & 0.0549 & 12.6 & 0.0596 \\
\hline & LTpL_L4 & 110 & 51 & 0.438 & 2.31 & 0.0392 & 12.6 & 0.0424 \\
\hline & LTpL_L5 & 116 & 53 & 1.000 & 2.31 & 0.0515 & 12.6 & 0.0019 \\
\hline \multirow[t]{19}{*}{ QL } & & {$[P]$} & & [D] & [D] & & [D] & \\
\hline & QL_post_I.1-L3 & 40 & 18 & 0.505 & 2.38 & 0.0384 & 7.4 & 0.0322 \\
\hline & QL_post_I.2-L4 & 53 & 24 & 0.505 & 2.38 & 0.0222 & 7.4 & $(0.0306)^{\mathrm{c}} 0.0186$ \\
\hline & QL_post_I.2-L3 & 31 & 14 & 0.505 & 2.38 & 0.0502 & 7.4 & 0.0421 \\
\hline & QL_post_I.2-L2 & 19 & 9 & 0.505 & 2.38 & 0.0348 & 7.4 & 0.0191 \\
\hline & QL_post_I.3-L1 & 28 & 13 & 0.505 & 2.38 & 0.0856 & 7.4 & 0.0445 \\
\hline & QL_post_I.3-L2 & 30 & 14 & 0.505 & 2.38 & 0.0504 & 7.4 & 0.0423 \\
\hline & QL_post_I.3-L3 & 50 & 23 & 0.505 & 2.38 & 0.0361 & 7.4 & 0.0303 \\
\hline & QL_mid_L3-12.3 & 13 & 6 & 0.624 & 2.38 & 0.0546 & 7.4 & 0.0284 \\
\hline & QL_mid_L3-12.2 & 14 & 7 & 0.624 & 2.38 & 0.0579 & 7.4 & 0.0301 \\
\hline & QL_mid_L3-12.1 & 24 & 11 & 0.624 & 2.38 & 0.0631 & 7.4 & 0.0328 \\
\hline & QL_mid_L2-12.1 & 20 & 9 & 0.624 & 2.38 & 0.0408 & 7.4 & 0.0212 \\
\hline & QL_mid_L4-12.3 & 12 & 5 & 0.624 & 2.38 & 0.0729 & 7.4 & 0.0379 \\
\hline & QL_ant_I.2-T12 & 15 & 7 & 0.624 & 2.38 & 0.1045 & 7.4 & 0.0543 \\
\hline & QL_ant_I.3-T12 & 29 & 13 & 0.624 & 2.38 & 0.1033 & 7.4 & 0.0537 \\
\hline & QL_ant_I.2-12.1 & 10 & 5 & 0.624 & 2.38 & 0.0999 & 7.4 & 0.0519 \\
\hline & QL_ant_I.3-12.1 & 19 & 9 & 0.624 & 2.38 & 0.0987 & 7.4 & 0.0512 \\
\hline & QL_ant_I.3-12.2 & 13 & 6 & 0.624 & 2.38 & 0.0929 & 7.4 & 0.0482 \\
\hline & QL_ant_I.3-12.3 & 15 & 7 & 0.624 & 2.38 & 0.0869 & 7.4 & 0.0451 \\
\hline \multirow[t]{18}{*}{ MF } & & {$[B 1]$} & & {$[\mathrm{R}]$} & [W-MF] & & {$[\mathrm{An}]$} & \\
\hline & MF_m1s & 40 & 18 & 0.661 & 2.27 & 0.0468 & 0 & 0.0195 \\
\hline & MF_m1t.1 & 42 & 19 & 0.730 & 2.27 & 0.0752 & 0 & 0.0225 \\
\hline & MF_m1t.2 & 36 & 17 & 0.730 & 2.27 & 0.0943 & 0 & 0.0283 \\
\hline & MF_m1t.3 & 60 & 28 & 0.730 & 2.27 & 0.1030 & 0 & 0.0309 \\
\hline & MF_m2s & 39 & 18 & 0.677 & 2.27 & 0.0454 & 0 & 0.0176 \\
\hline & MF_m2t.1 & 39 & 18 & 0.727 & 2.27 & 0.0639 & 0 & 0.0194 \\
\hline & MF_m2t.2 & 99 & 46 & 0.727 & 2.27 & 0.0809 & 0 & 0.0246 \\
\hline & MF_m2t.3 & 99 & 46 & 0.727 & 2.27 & 0.0917 & 0 & 0.0279 \\
\hline & MF_m3s & 54 & 25 & 0.661 & 2.27 & 0.0397 & 0 & 0.0165 \\
\hline & MF_m3t.1 & 52 & 24 & 0.709 & 2.27 & 0.1028 & 0 & 0.0342 \\
\hline & MF_m3t.2 & 52 & 24 & 0.709 & 2.27 & 0.0854 & 0 & 0.0284 \\
\hline & MF_m3t.3 & 52 & 24 & 0.709 & 2.27 & 0.0854 & 0 & 0.0284 \\
\hline & MF_m4s & 47 & 21 & 0.562 & 2.27 & 0.0372 & 0 & 0.0235 \\
\hline & MF_m4t.1 & 47 & 21 & 0.667 & 2.27 & 0.0548 & 0 & 0.0222 \\
\hline & MF_m4t.2 & 47 & 21 & 0.667 & 2.27 & 0.0734 & 0 & 0.0297 \\
\hline & MF_m4t.3 & 47 & 21 & 0.667 & 2.27 & 0.0848 & 0 & 0.0344 \\
\hline & MF_m5s & 23 & 10 & 0.562 & 2.27 & 0.0147 & 0 & 0.0093 \\
\hline
\end{tabular}


Table 1 Continued

\begin{tabular}{|c|c|c|c|c|c|c|c|c|}
\hline Muscle & Name & PCSA & $F_{o}^{M}$ & $\ell^{f} / \ell^{M T}$ & $\ell^{S}$ & $\ell_{o}^{M}$ & $\alpha$ & $\ell_{S}^{T}$ \\
\hline \multirow[t]{9}{*}{ MF } & & {$[\mathrm{B} 1]$} & & {$[\mathrm{R}]$} & [W-MF] & & [An] & \\
\hline & MF_m5t.1 & 23 & 10 & 0.667 & 2.27 & 0.0759 & 0 & 0.0308 \\
\hline & MF_m5t.2 & 23 & 10 & 0.667 & 2.27 & 0.0568 & 0 & 0.0230 \\
\hline & MF_m5t.3 & 23 & 10 & 0.667 & 2.27 & 0.0175 & 0 & 0.0071 \\
\hline & MF_m1.laminar & 19 & 9 & 0.681 & 2.27 & 0.0313 & 0 & 0.0119 \\
\hline & MF_m2.laminar & 22 & 10 & 0.681 & 2.27 & 0.0269 & 0 & 0.0102 \\
\hline & MF_m3.laminar & 23 & 11 & 0.681 & 2.27 & 0.0262 & 0 & 0.0099 \\
\hline & MF_m4.laminar & 17 & 8 & 0.681 & 2.27 & 0.0286 & 0 & 0.0109 \\
\hline & MF_m5.laminar & 36 & 17 & 0.681 & 2.27 & 0.0256 & 0 & 0.0097 \\
\hline \multirow[t]{7}{*}{ EO } & & {$[\mathrm{S}]$} & & est. [G] & [D] & & [D] & \\
\hline & EO1 & 196 & 90 & 0.389 & 2.83 & 0.0359 & 0 & 0.0570 \\
\hline & $\mathrm{EO} 2$ & 232 & 107 & 0.410 & 2.83 & 0.0379 & 0 & 0.0552 \\
\hline & $\mathrm{EO} 3$ & 243 & 112 & 0.455 & 2.83 & 0.0384 & 0 & 0.0466 \\
\hline & $\mathrm{EO} 4$ & 234 & 108 & 0.470 & 2.83 & 0.0393 & 0 & 0.0448 \\
\hline & EO5 & 273 & 126 & 0.480 & 2.83 & 0.0471 & 0 & 0.0515 \\
\hline & EO6 & 397 & 183 & 0.500 & 2.83 & 0.0565 & 0 & 0.0571 \\
\hline \multirow[t]{7}{*}{ IO } & & {$[\mathrm{S}]$} & & est. [G] & [D] & & [D] & \\
\hline & IO1 & 185 & 85 & 0.400 & 2.83 & 0.0422 & 0 & 0.0640 \\
\hline & IO2 & 224 & 103 & 0.400 & 2.83 & 0.0435 & 0 & 0.0659 \\
\hline & IO3 & 226 & 104 & 0.400 & 2.83 & 0.0517 & 0 & 0.0783 \\
\hline & IO4 & 268 & 123 & 0.600 & 2.83 & 0.0697 & 0 & 0.0470 \\
\hline & IO5 & 235 & 108 & 0.600 & 2.83 & 0.0568 & 0 & 0.0383 \\
\hline & IO6 & 207 & 95 & 0.600 & 2.83 & 0.0544 & 0 & 0.0367 \\
\hline \multirow[t]{15}{*}{ LD } & & [B-LD] & & est. [B-LD] & & & & \\
\hline & LD_L1 & 90 & 41 & 0.790 & 2.3 & 0.3161 & 0 & 0.0692 \\
\hline & LD_L2 & 90 & 41 & 0.790 & 2.3 & 0.3383 & 0 & 0.0741 \\
\hline & LD_L3 & 110 & 51 & 0.790 & 2.3 & 0.3551 & 0 & 0.0778 \\
\hline & LD_L4 & 110 & 51 & 0.790 & 2.3 & 0.3719 & 0 & 0.0815 \\
\hline & LD_L5 & 110 & 51 & 0.800 & 2.3 & 0.3902 & 0 & 0.0801 \\
\hline & LD_T7 & 40 & 18 & 0.800 & 2.3 & 0.2238 & 0 & 0.0460 \\
\hline & LD_T8 & 40 & 18 & 0.800 & 2.3 & 0.2325 & 0 & 0.0477 \\
\hline & LD_T9 & 40 & 18 & 0.840 & 2.3 & 0.2570 & 0 & 0.0402 \\
\hline & LD_T10 & 60 & 28 & 0.840 & 2.3 & 0.2797 & 0 & 0.0438 \\
\hline & LD_T11 & 60 & 28 & 0.800 & 2.3 & 0.2848 & 0 & 0.0585 \\
\hline & LD_T12 & 50 & 23 & 0.800 & 2.3 & 0.3032 & 0 & 0.0623 \\
\hline & LD_R11 & 60 & 28 & 0.800 & 2.3 & 0.2407 & 0 & 0.0494 \\
\hline & LD_R12 & 40 & 18 & 0.800 & 2.3 & 0.2445 & 0 & 0.0502 \\
\hline & LD_Il & 70 & 32 & 0.950 & 2.3 & 0.4321 & 0 & 0.0187 \\
\hline
\end{tabular}

The source of this data is given at the top of each muscle column

est. implies these data were not explicitly given, but it was determined graphically or by description

${ }^{a}$ Data for $\ell^{f} / \ell^{M T}$ estimated graphically from Fig. 2 (ILpT), Fig. 6 (LTpT), and Fig. 8 (LTpL) of [M]

${ }^{\mathrm{b}}$ Value should be close to 1 based on Fig. 4 of [M], but using this value causes the model to produce muscle force patterns that are inaccurate

${ }^{c} \ell_{s}^{T}$ value should assume the value given in parenthesis, but doing this causes the model to produce muscle force patterns that are inaccurate

Key: [Ar]: Arnold et al. (2010), [An]: Anderson et al. (2005) [B1]: Bogduk et al. (1992a), [B-LD]: Bogduk et al. (1998), [B-Ps]: Bogduk et al. (1992b), [D]: Delp et al. (2001), [G]: Gray (1980), [M]: Macintosh and Bogduk (1987), [P]: Phillips et al. (2008), [R]: Rosatelli et al. (2008), [S]: Stokes and Gardner-Morse (1999), [W]: Ward et al. (2009a), and [W-MF]: Ward et al. (2009b) 
Table 2 Comparison of previously reported PCSA $\left(\mathrm{mm}^{2}\right)$ values in lumbar spine models

\begin{tabular}{lccccc}
\hline $\begin{array}{l}\text { Muscle group } \\
\text { Mean age \& Sex }\end{array}$ & $\begin{array}{l}\text { Our model } \\
\mathrm{n} / \mathrm{a}\end{array}$ & $\begin{array}{l}{[\mathrm{M}]} \\
26, \mathrm{M}\end{array}$ & $\begin{array}{l}{[\mathrm{D}]} \\
67, \mathrm{M} \& \mathrm{~F}\end{array}$ & $\begin{array}{l}\text { [A] } \\
\mathrm{n} / \mathrm{a}\end{array}$ & $\begin{array}{r}{[\mathrm{McG}]} \\
\mathrm{n} / \mathrm{a}, \mathrm{M}\end{array}$ \\
\hline QL & 434 & 526 & 120 & 313 & \\
RA & 567 & 905 & 260 & 567 & \\
LD & 970 & 2,174 & & & \\
MD & 1,058 & & & 765 & \\
IO & 1,345 & 1,026 & & 1,345 & 1,950 \\
EO & 1,575 & 1,006 & & 1,575 & 1,600 \\
Psoas & 1,463 & 1,949 & & 1,374 & 850 \\
ES & 2,788 & 2,595 & 1,000 & 3,002 & \\
LT & 1,608 & & 590 & 1,709 & \\
IL & 1,180 & & 410 & 1,293 & \\
\hline
\end{tabular}

length in the following manner

$$
\ell_{o}^{M}=\ell^{M} \times \frac{\ell_{o}^{S}}{\ell^{S}},
$$

where $\ell_{o}^{S}$ is the optimal sarcomere length of the animal being studied, $\ell^{S}$ is the measured resting sarcomere length, and $\ell^{M}$ is the resting muscle fiber length. We utilized an optimal sarcomere length of $2.8 \mu \mathrm{m}$ in line with reported optimal sarcomere lengths in humans in the range of 2.7 to $2.8 \mu \mathrm{m}$ (Walker and Schrodt 1974; Lieber et al. 1994). The resting sarcomere lengths for the erector spine, quadratus lumborum, and rectus abdominis muscles were based on values reported by Delp et al. (2001). Recent extensive studies on the multifidus and psoas major (Ward et al. 2009a,b,c) were used to determine the sarcomere length and fiber lengths of these groups. As there was no such data for the latissimus dorsi group, we approximated the value by taking an average of the back muscles to get a resting sarcomere length of $2.3 \mu \mathrm{m}$. Our model assumes the resting sarcomere length of a muscle group is also consistent among all its fascicles.

Due to a tendon's relatively high stiffness (about $180 \mathrm{~N} / \mathrm{mm}$ ) (Lichtwark and Wilson 2008), fiber force is highly sensitive to the accuracy of the data used, and several estimation algorithms have been developed to determine tendon slack length (Manal and Buchanan 2004; Lee et al. 2008). However, since sufficient data do not exist in the literature on the tendon slack lengths of all the fascicles of the lumbar musculature, they were estimated by generalizing the relationship between muscle length and tendon slack length,

$\ell_{S}^{T} \approx \ell^{M T}-\ell^{M} \cos (\alpha)$,

where $\alpha$ is the muscle fiber's pennation angle and $\ell^{M T}$ and $\ell^{M}$ are musculotendon length and known muscle fiber length, respectively, in the neutral position. Note that, as this approximation employs the resting muscle fiber length $\ell^{M}$, the tendon slack length can also be thought of as the length of the tendon when the muscle is in the neutral position.

\section{Joint kinematics}

The joints connecting the lumbar bodies are each modeled as a six degree-of-freedom custom joint. As is standard practice in dynamics, it is convenient to define a set of coordinates $\left\{q_{1}, q_{2}, \ldots, q_{30}\right\}$ to describe the degrees of freedom. Following Vasavada et al. (1998), we then impose 27 integrable constraints of the form

$q_{K}=f_{K}\left(q_{1}, q_{2}, q_{3}\right), \quad(K=4, \ldots, 30)$,

to reduce the model of the lumbar spine to a three degreeof-freedom system. In particular, $q_{1}, q_{2}$, and $q_{3}$ parameterize the flexion-extension, axial rotation, and lateral bending respectively, of the rotation of the thoracic spine segment $\mathcal{T}_{12}$ relative to the sacrum $\mathcal{S}_{1}$.

In agreement with White and Panjabi (1978b), we have assumed that the motion of each of the lumbar vertebrae is assumed to be linear functions of the coordinate of interest, namely flexion-extension, axial rotation, and lateral bending. That is,

$y=k x$,

where $x$ is one of the three degrees of freedom, $y$ is the related vertebral coordinate, and $k$ is the slope of the function. For example, if $x$ represents the total lateral bending motion of the spine, and $y$ is the lateral bending at the $\mathcal{L}_{4} / \mathcal{L}_{5}$ joint, then the slope $k$ is 0.1812 (cf. Table 3).

The values used to determine the amount of flexionextension motion were taken from Wong et al. (2006), while data from Rozumalski et al. (2008) were utilized for lateral bending motion. However, these data were normalized to $25^{\circ}$ in accordance with the ROM of the lumbar spine in lateral 
Table 3 Slope, $k$ defining the linear relationship between net lumbar motion and motion at the individual vertebrae

Key: [F]: Fujii et al. (2007), [R]: Rozumalski et al. (2008), [W]: Wong et al. (2006)

\begin{tabular}{llll}
\hline Body & Flexion extension $[\mathrm{W}]$ & Lateral bending $[\mathrm{R}]$ & Axial Rotation $[\mathrm{F}]$ \\
\hline $\mathcal{L}_{1}$ & 0.255 & 0.188 & 0.0288889 \\
$\mathcal{L}_{2}$ & 0.231 & 0.25 & 0.0311111 \\
$\mathcal{L}_{3}$ & 0.204 & 0.2452 & 0.037778 \\
$\mathcal{L}_{4}$ & 0.185 & 0.1812 & 0.037778 \\
$\mathcal{L}_{5}$ & 0.125 & 0.1356 & 0.0355556 \\
ROM & $\left(-70^{\circ}\right.$ to $\left.20^{\circ}\right)$ & $\left(-25^{\circ}\right.$ to $\left.25^{\circ}\right)$ & $\left(-45^{\circ}\right.$ to $\left.45^{\circ}\right)$
\end{tabular}

bending as mentioned in the study by Troke et al. (2001). Axial rotation motion of the model was based on data presented in Fujii et al. (2007). ${ }^{1}$ Table 3 summarizes the slope values used for each of the five lumbar levels.

\section{Musculoskeletal model results}

In order to build the model, we began with a generic representation of the torso and lower extremity created by Delp et al. (1990) and modified by Arnold et al. (2010) using digitized bone geometry from a male subject with a height of $170 \mathrm{~cm}$. The 5 lumbar vertebra were then each individually translated and rotated to match the correct spinal posture. The lumbar lordosis was subsequently compared with data presented in Cholewicki et al. (1996) and Meakin et al. (2008) to ensure accuracy. The vertebral geometries were correlated with the anatomical studies by Gilad and Nissan (1986), Nissan and Gilad (1986), and those of Panjabi et al. (1992), and the intervertebral heights adjusted according to the ratio of vertebral height and disc height. That is, we took the given 3D bone geometry from the existing lumbar spine bone geometry file in OpenSim, placed point markers on particular anatomical locations (e.g., top front point, bottom front point), and then used these markers to get values for the front vertebral heights and rear vertebral heights of each lumbar vertebrae. Then, using the ratio of vertebral height to disc height given in the literature, we estimated the intervertebral disc height.

The locations of the instantaneous axis of rotation (IAR) of each of the five joints were taken from the kinematic radiographic study by Pearcy and Bogduk (1988) of subjects engaging in flexion and extension movement from the upright position. Figure 4 shows the IAR location of each of the five joints and was set to the mean of the IAR location of the ten individuals as depicted in Fig. 9 of (Pearcy and Bogduk 1988).

${ }^{1}$ Cf. text on pages 1869 and 1890 of the results section of Fujii et al. (2007).

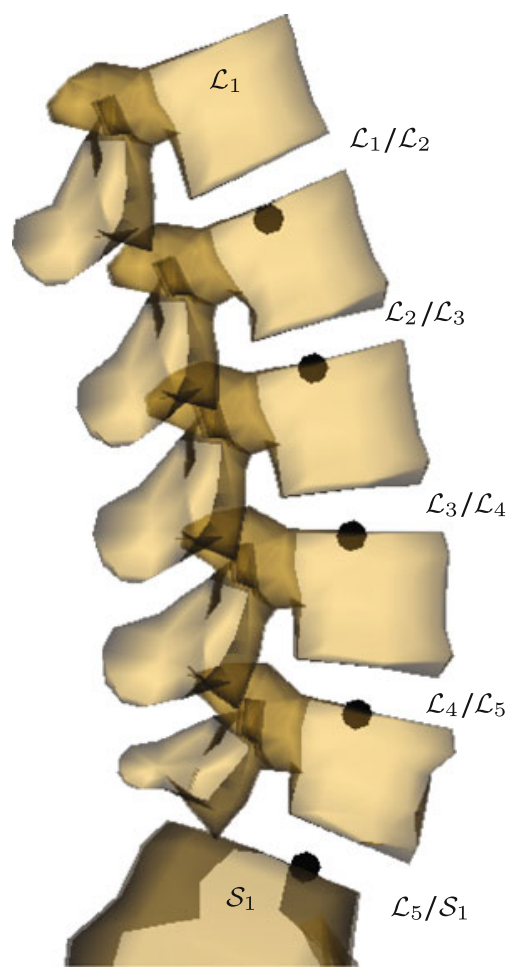

Fig. 4 Locations of the instantaneous axis of rotation denoted by $\bullet$ for the 5 lumbar intervertebral joints based on the mean values reported by Pearcy and Bogduk (1988)

The masses and moments of inertia of each vertebral body were determined from the extensive examinations by Pearsall et al. $(1994,1996)$ and presented in Table $4 .^{2}$

The muscle architecture as described in Sect. 2.1 was modeled based on anatomic bone locations (Bogduk 2005). Figure 5 depicts the musculoskeletal model of the lumbar spine detailed here in the neutral posture (a) and flexed by $50^{\circ}$ (b).

\subsection{Moment arms during flexion-extension}

The tendency of a muscle to rotate a bone about a joint is described by the moment arm of the muscle. The moment

\footnotetext{
2 The moments of inertia were altered slightly to satisfy the inequality constraint $I_{i i}+I_{j j} \geq I_{k k}, i \neq j \neq k \neq i$
} 
Table 4 Mass and inertia estimates for the trunk as determined by Pearsall et al. (1996) (coordinates have been altered to correspond with the coordinate convention used in the OpenSim model)

\begin{tabular}{|c|c|c|c|c|c|c|}
\hline Level & Mass (g) & Trunk mass (\%) & Body mass (\%) & $I_{x x}$ & $I_{y y}\left(\mathrm{~kg} \mathrm{~cm}^{2}\right)$ & $I_{z z}$ \\
\hline Upper trunk & 13,149 & 44.6 & 18.5 & $1,650.0$ & $1,500.0$ & 1250.0 \\
\hline $\mathcal{L}_{1}$ & 1,677 & 5.7 & 2.4 & 111.3 & 175.3 & 64 \\
\hline $\mathcal{L}_{2}$ & 1,689 & 5.7 & 2.4 & 109.1 & 168.2 & 59.1 \\
\hline $\mathcal{L}_{3}$ & 1,670 & 5.7 & 2.3 & 106.6 & 160.8 & 55.1 \\
\hline $\mathcal{L}_{4}$ & 1,799 & 6.2 & 2.6 & 112.3 & 164.3 & 52.0 \\
\hline $\mathcal{L}_{5}$ & 1,824 & 6.3 & 2.6 & 121.9 & 176.5 & 54.6 \\
\hline Pelvis \& Sacrum* & 7,486 & 25.6 & 10.7 & 750.0 & 800.0 & 300.0 \\
\hline
\end{tabular}

* These numbers represent the total of the pelvis/sacrum values. For simplicity, the model assumes that the sacrum is welded to the pelvis, and only the sacrum $\mathcal{S}_{1}$ has non-zero mass and moment of inertia properties
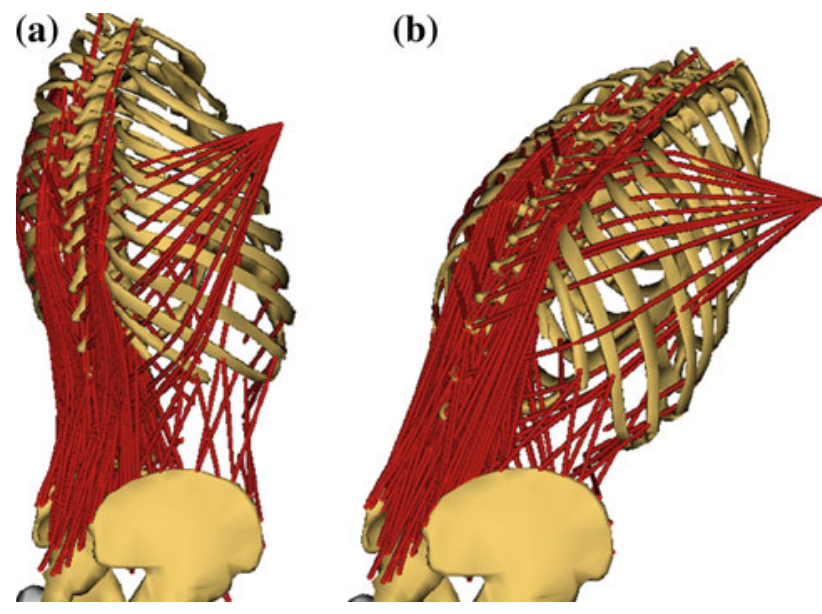

Fig. 5 A detailed musculoskeletal model of the lumbar spine consisting of 238 muscle fascicles, 13 rigid bodies, and 5 intervertebral joints in the a Neutral posture and $\mathbf{b} 50^{\circ}$ flexion position

arm is a useful parameter to study as it both defines the function of a muscle about a joint and provides a straightforward metric for validating the accuracy of muscle paths used in a given musculoskeletal model (Pandy 1999).

Numerically, it is common to define the moment arm of a muscle about the $i$ th-generalized coordinate as the negative of the change in effective length of the musculotendon actuator system $\ell_{\text {effec }}^{M T}$ with respect to the change in the $i$ thgeneralized coordinate $q_{i}$,

$\rho_{i}=-\frac{\partial \ell_{\mathrm{effec}}^{M T}}{\partial q_{i}}$.

Here, the effective length of the musculotendon actuator system is defined as the length of the portion of the muscle that spans the joint of interest. That is, if two bodies A and B of a given musculoskeletal model have attachment points $P_{1}$ through $P_{m-1}$ on body A and $P_{m}$ through $P_{n}$ on body B, with the line connecting point $P_{m}$ to $P_{m-1}$ spanning the joint of interest, the moment arm of the muscle depends only on the change in the effective muscle length, $\left\|\mathbf{r}_{P m-1}-\mathbf{r}_{P m}\right\|$ (cf.

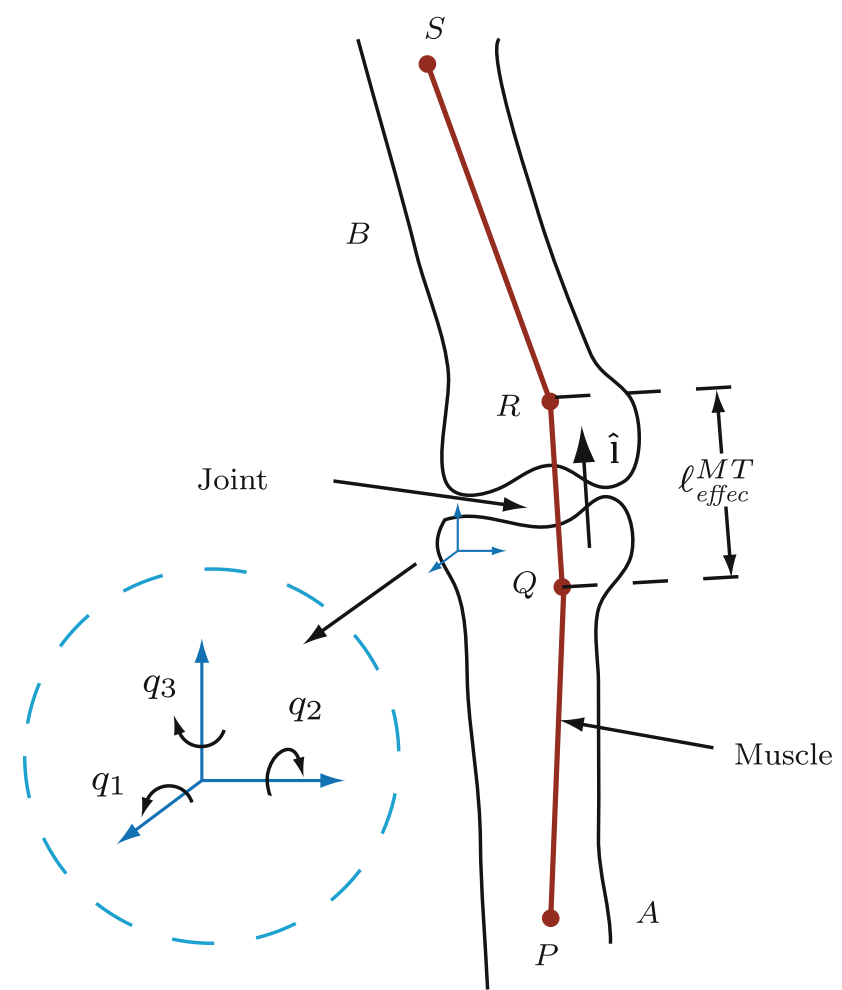

Fig. 6 The points $P, Q, R$, and $S$ define the muscle path of the muscle shown with the points $P$ and $Q$ fixed in body $A$ while the points $R$ and $S$ are fixed in body $B$. The effective length of the muscle $\ell_{\mathrm{effec}}^{M T}$ is equal to the length of the line joining the points $Q$ and $R$ in the diagram. The figure also depicts the generalized coordinates $q_{1}, q_{2}$, and $q_{3}$ used to compute the moment arms of the muscle as defined by Eq. (7)

Figure 6 for the case $n=4)$. Equation (7) corresponds to Eq. (4) of Pandy (1999), Eq. (3) of Erdemir et al. (2007), and is the method utilized in OpenSim to determine the moment arms (Delp and Loan 1995).

Figure 7 presents a plot of the mean and standard deviation boundaries of the moment arms of the seven relevant muscle groups about the $\mathcal{L}_{5} / \mathcal{S}_{1}$ joint for motion ranging from $20^{\circ}$ flexion to $20^{\circ}$ extension (corresponding to $2.5^{\circ}$ degrees of 
Fig. 7 The moment arms for the primary lumbar muscle groups about the $\mathcal{L}_{5} / \mathcal{S}_{1}$ joint during flexion-extension motion of the lumbar spine. The lines represent the mean of all fascicles within that muscle group and the shaded region represents \pm 1 standard deviation
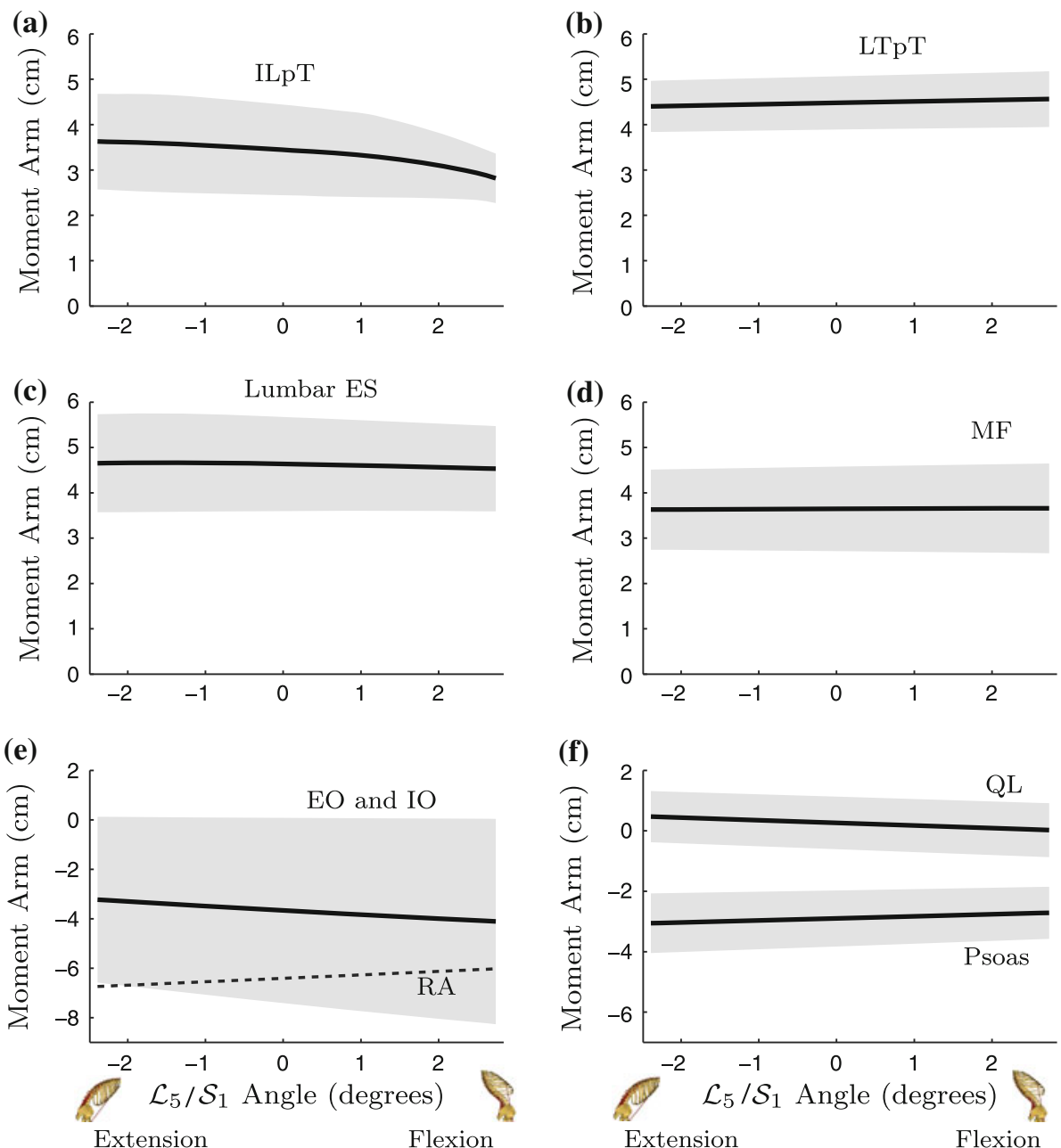

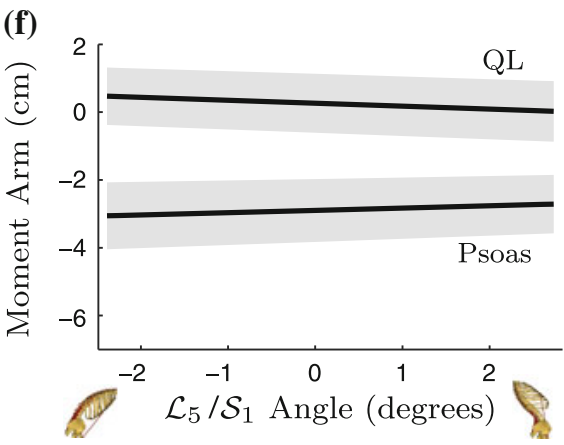

Extension

Flexion flexion and extension at the $\mathcal{L}_{5} / \mathcal{S}_{1}$ joint, as can be seen from Table 3). Only the muscles fascicles crossing the $\mathcal{L}_{5} / \mathcal{S}_{1}$ joint were included in the calculation in line with Eq. (7). For this reason, the moment arm of the LD muscle group is not shown.

We found that the moment arms of the iliocostalis lumborum pars thoracis muscle group decreased with extension, while those of the longissimus thoracis pars thoracis muscle group remained constant throughout the range of motion. In the interest of brevity, we elected to represent the moment arms of the iliocostalis lumborum pars lumborum and longissimus thoracis pars lumborum muscle groups using a single curve as the moment arms of these two muscle groups were similar for the range of motion analyzed (cf. Fig.7c). Overall, the moment arms of the erector spinae muscle groups agree quantitatively with the anatomic measurements provided in Bogduk et al. (1992a), Macintosh et al. (1993) and Jorgensen et al. (2003), while the moment arms of the multifidus muscle group about the $\mathcal{L}_{5} / \mathcal{S}_{1}$ joint (Fig. 7d) concur with those given in Macintosh et al. (1993). Similar quantitative agreements were found for the moment arms of the rectus abdominis, the obliques, the psoas, and the quadratus lumborum muscle groups with the moment arms reported in Jorgensen et al. (2001) and Phillips et al. (2008). The small moment arms of the internal and external obliques, the psoas, as well as the quadratus lumborum muscle groups are as expected since these muscle groups exert little influence as flexors of the lumbar spine (Bogduk 2005).

From Eq. 7, it is apparent that negative moment arms occur when the change in effective muscle length and change in joint rotation are both of the same sign. Hence, the negative values for the abdominal and psoas muscle groups (Fig. 7e, f) indicate that these two muscles are flexors rather than an extensors. We took the absolute value of these muscles for comparison with previous anatomical studies as these determined the moment arms via direct measurements of the muscles to predefined points of rotation.

It is illustrative to point out that the moment arms of the individual muscle fascicles of a given muscle group may not always follow the same pattern nor have the same magnitude. For example, the moment arm of the deep MF muscle that goes from the $\mathcal{L}_{4}$ vertebra to $\mathcal{S}_{1}\left(\mathrm{MF} \_\right.$m4.laminar) decreases while the deep MF muscle from $\mathcal{L}_{5}$ to $\mathcal{S}_{1}$ 


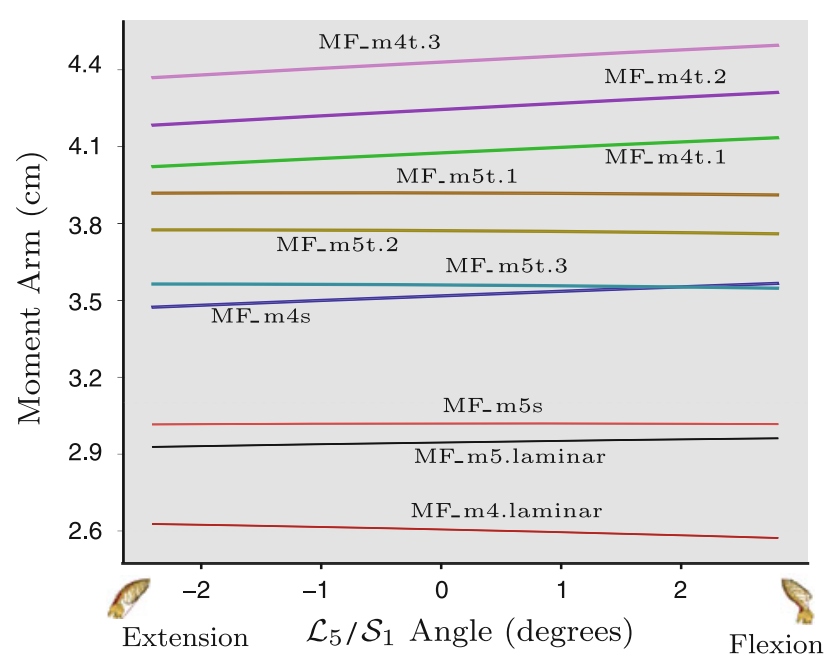

Fig. 8 The moment arms of the individual muscle fascicles of the multifidus muscle group about the $\mathcal{L}_{5} / \mathcal{S}_{1}$ joint during flexion-extension motion of the lumbar spine. Only those muscle fascicles crossing the joint are depicted. Our notation follows the convention used by Bogduk et al. (1992a), Macintosh et al. (1993) where mKs indicate the fascicles from $\mathcal{L}_{K}$ that arise from the shaft of the spinous process and $\mathrm{mKt} .1, \mathrm{mKt} .2$, and $\mathrm{mKt} .3$ correspond to the three fascicles from the tip of the $\mathcal{L}_{K}$ spinous process. The m4.laminar and m5.laminar fascicles, on the other hand, correspond to the deep multifidus fascicles spanning from $\mathcal{L}_{4}$ to $\mathcal{S}_{1}$ and from $\mathcal{L}_{5}$ to $\mathcal{S}_{1}$, respectively

body (MF_m5.laminar), as well as the superficial fibers arising from the $\mathcal{L}_{4}$ spinous process (MF_m4s, MF_m4t.1, MF_m4t.2, and MF_m4t.3), all increases as the spine is flexed (cf. Figure 8).

\section{Discussion and conclusions}

In this paper, we have presented a novel lumbar spine model using OpenSim, an open-source musculoskeletal simulation software. This lumbar spine model is currently, to the best of our knowledge, the most physiologically detailed noncommercial musculoskeletal model available. It is primarily intended as an analytic tool for researchers to analyze spinal kinematics in the hopes of further improving our understanding of the pathology behind, and potential remedies for, chronic lower back pain.

It has been shown that specific muscular activation patterns are necessary to maintain spinal stability (Brown et al. 2006; Cholewicki et al. 2000; El-Rich et al. 2004). This model is an ideal starting point for studying the hypothesis that lower back pain is a consequence of joint degeneration in combination with altered muscle activation patterns. In particular, this model is well suited to study the phenomena of antagonistic muscle co-activation during lifting and the concomitant effects on spinal stability. Electromyographic data from subjects asked to perform kinematic tasks that require proprioceptive feedback (Moseley et al. 2003; Brown and McGill 2009) could serve as input with the ensuing kinematics studied and compared with those obtained from subjects with lower back pain to identify possible sources of treatment.

While the model can be used to analyze tasks such as the effect of lifting technique, posture, and muscle imbalance on the joint reaction loads and muscle recruitment strategy, motions that are governed by the central nervous system (e.g., reflex-type motions) can only be simulated by the model if the user specifies the associated muscle activation patterns produced under those conditions. It is hoped that the existence of our model will spur the formation of a publicly available database containing the relevant muscle activation patterns that can be accessed and modified by the community of researchers interested in analyzing lumbar spine kinematics.

Despite the complexity of the model, there are still a number of improvements that need to be incorporated. For example, coupled motion was not included in our model despite data showing that lateral bending and axial rotation are usually accompanied by motion in the other two degrees-of-freedom (White and Panjabi 1978a; Pearcy and Tibrewal 1984; Ochia et al. 2006; Fujii et al. 2007; Kozanek et al. 2009; Li et al. 2009). This was because the ensuing change in the results was not significant enough to justify the increase in computational cost as a result of the increase in the model's complexity. The incorporation of a stiffness matrix to model the intervertebral joint kinematics (Metzger et al. 2010; Panjabi et al. 1976; Stokes et al. 2002; O'Reilly et al. 2009) would overcome this in an analytically and numerically tractable manner. Aside from allowing for coupled motion, the stiffness matrix representation of the joint would also permit a more transparent relationship between the joint displacements and rotations and the accompanying forces and moments.

Needless to say, it is encouraging to note that a number of musculoskeletal models of the spine that employ 6 degreeof-freedom bushing elements-akin to a diagonal stiffness matrix - to model the intervertebral joint have recently been developed (Huynh et al. 2010; Monteiro et al. 2011), but none of these allow for the more complex off-diagonal loaddisplacement coupling evidenced in the joint. We are in the process of improving upon this functionality in OpenSim and plan to employ this stiffness matrix in a future model in lieu of constraint functions.

However, the effects of the other passive structures in the lumbar spine, such as the ligaments and facet joints on constraining the lumbar motion, have not been included. These passive structures are hypothesized to play a synergistic role with the muscles in maintaining spinal stability (Granata 2006). While the ligament effects can be incorporated into the 
stiffness matrix formulation mentioned previously, the constraining effects of the facet forces are more involved due to the geometry of (and forces in) the facet joints.

Our model also currently mimics the action of the abdominal muscles using straight line muscle paths that may not accurately replicate the action of intra-abdominal pressure (IAP) on spinal kinematics. This biomechanically oversimplifies the contribution of the abdominal wall to both reducing spinal loading (Stokes et al. 2010) and increasing lumbar stability (Cholewicki et al. 1999). Nevertheless, a more accurate representation of the IAP using, for example, an elastic membranous pressure vessel (Daggfeldt and Thorstensson 1997) or more realistic three-dimensional curved muscle paths (Stokes et al. 2010) is beyond the current scope of the OpenSim software. Limitations in the program and a lack of data also meant that we were forced to model the IAR as fixed in the body below it despite studies showing that the location and orientation of the IAR differ depending on the primary motion (White and Panjabi 1978a; Woltring et al. 1985) and that the arc length pathways of the IAR are longer in patients with lumbar segmental instability (Ahmadi et al. 2009).

The wide inter-subject variation, for example, with respect to lumbar curvature, muscle cross-sectional area, and muscle strength necessarily means that the generality of the model renders it unsuitable for a subject specific analysis. Unfortunately, this is a problem common to all generic musculoskeletal models. Nevertheless, one of the main advantages of the model presented in this paper is its opensource nature that naturally allows for further improvements and modifications to be performed in a straightforward and simple manner by other spinal researchers. The availability of a model such as ours in the public domain permits those interested in modeling the dynamics and kinematics of the lumbar spine to do so with relative ease without having to construct a model from the ground up. Furthermore, this allows for different research groups utilizing the model to compare their results in a more transparent manner. Of particular benefit with regard to the open-source nature of our model is the ease with which our model can be integrated with existing OpenSim models. For example, assimilating our model with existing models of the limbs and other sections of the spine (Delp et al. 1990; Vasavada et al. 1998; Holzbaur et al. 2005; Crabtree and Higginson 2009; Ramsay et al. 2009; Arnold et al. 2010; Xiao and Higginson 2010) will hopefully lead to more accurate musculoskeletal models for the purposes of improved analysis of specific physiological parameters of interest.

Nonetheless, we caution that the results obtained using the model are dependent on the validity of the input parameters used to construct the model and, in some cases, cannot be validated due to the current lack of data in the literature. This sentiment was also echoed in de Zee et al. $(2003,2007)$ with regard to their commercial AnyBody model. However, we are optimistic that the existence of lumbar musculoskeletal models such as ours will encourage lumbar researchers into providing the necessary experimental data in line with the research conducted. Additionally, the open-source nature of our model naturally lends itself to improvement by the biomedical research community, such that the limitations mentioned above may be addressed in a straightforward, collaborative manner.

Acknowledgments The authors thank Professor Scott Delp and the OpenSim team for their generous technical support with this software, acknowledge the inspiration provided by the cervical spine model in Vasavada et al. (1998), and express their appreciation to the reviewers for their helpful comments and suggestions. The work of the authors was partially supported by the National Science Foundation of the United States under Grant No. CMMI 0726675.

Conflict of interest The authors report no conflicts of interest.

Open Access This article is distributed under the terms of the Creative Commons Attribution Noncommercial License which permits any noncommercial use, distribution, and reproduction in any medium, provided the original author(s) and source are credited.

\section{References}

Adams MA (2004) Biomechanics of back pain. Acupunct Med 22(4): 178-188

Ahmadi A, Maroufi N, Behtash H, Zekavat H, Parnianpour M (2009) Kinematic analysis of dynamic lumbar motion in patients with lumbar segmental instability using digital videofluoroscopy. Eur Spine J 18(11):1677-1685

Anderson J, Hsu A, Vasavada AN (2005) Morphology, architecture, and biomechanics of human cervical multifidus. Spine 30(4):E86-E91

Arjmand N, Shirazi-Adl A (2006) Model and in vivo studies on human trunk load partitioning and stability in isometric forward flexions. J Biomech 39(3):510-521

Arnold EM, Ward SR, Lieber RL, Delp SL (2010) A model of the lower limb for analysis of human movement. Ann Biomed Eng 38(2):269-279

Bogduk N (1980) A reappraisal of the anatomy of the human lumbar erector spinae. J Anat 131(3):525-540

Bogduk N (2005) Clinical anatomy of the lumbar spine and sacrum. 4. Churchill Livingstone, New York

Bogduk N, Johnson G, Spalding D (1998) The morphology and biomechanics of latissimus dorsi. Clin Biomech 13(6):377-385

Bogduk N, Macintosh JE, Pearcy MJ (1992a) A universal model of the lumbar back muscles in the upright position. Spine 17(8):897-913

Bogduk N, Pearcy MJ, Hadfield G (1992b) Anatomy and biomechanics of psoas major. Clin Biomech 7(2):109-119

Brown SHM, McGill SM (2009) The intrinsic stiffness of the in vivo lumbar spine in response to quick releases: implications for reflexive requirements. J Electromyography Kinesiology 19(5):727736. doi:10.1016/j.jelekin.2008.04.009

Brown SHM, Vera-Garcia F, McGill S (2006) Effects of abdominal muscle coactivation on the externally preloaded trunk: variations in motor control and its effect on spine stability. Spine 31(13):E387E393

Cholewicki J, Crisco JJ, Oxland T, Yamamoto I and Panjabi MM (1996) Effects of posture and structure on three-dimensional coupled rotations in the lumbar spine: a biomechanical analysis. Spine 21(21):2421-2428 
Cholewicki J, Juluru K, McGill S (1999) Intra-abdominal pressure mechanism for stabilizing the lumbar spine. J Biomech 32(1):1317

Cholewicki J, McGill S, Norman RW (1995) Comparison of muscle forces and joint load from an optimization and EMG assisted lumbar spine model: towards development of a hybrid approach. J Biomech 28(3):321-331

Cholewicki J, Simons AP, Radebold A (2000) Effects of external trunk loads on lumbar spine stability. J Biomech 33(11):1377-1385

Crabtree CA, Higginson JS (2009) Modeling neuromuscular effects of ankle foot orthoses (afos) in computer simulations of gait. Gait \& Posture 29(1):65-70. doi:10.1016/j.gaitpost.2008.06.004

Daggfeldt K, Thorstensson A (1997) The role of intra-abdominal pressure in spinal unloading. J Biomech 30(11-12):1149-1155

de Zee M, Hansen L, Andersen TB, Wong C, Rasmussen J, Simonsen EB (2003) On the development of a detailed rigid-body spine model. In: Proceedings of international congress on computational bioengineering, Spain,5pp

de Zee M, Hansen L, Wong C, Rasmussen J, Simonsen EB (2007) A generic detailed rigid-body lumbar spine model. J Biomech 40(6):1219-1227

Delp SL, Anderson F, Arnold AS, Loan JP, Habib A, John C, Guendelman E, Thelen DG (2007) OpenSim:open-source software to create and analyze dynamic simulations of movement. IEEE Trans Biomed Eng 54(11):1940-1952

Delp SL, Loan JP (1995) A graphics-based software system to develop and analyze models of musculoskeletal structures. Comput Biol Med 25(1):21-34

Delp SL, Loan JP, Hoy MG, Zajac FE, Topp EL, Rosen JM (1990) An interactive graphics-based model of the lower extremity to study orthopaedic surgical procedures. IEEE Trans Biomed Eng 37(8): 757-767. doi:10.1109/10.102791

Delp SL, Suryanarayanan S, Murray W, Uhlir J, Triolo RJ (2001) Architecture of the rectus abdominis, quadratus lumborum, and erector spinae. J Biomech 34(3):371-375

El-Rich M, Shirazi-Adl A, Arjmand N (2004) Muscle activity, internal loads, and stability of the human spine in standing postures: combined model and in vivo studies. Spine 29(23):2633-2642

Erdemir A, McLean S, Herzog W, vanden Bogert AJ (2007) Modelbased estimation of muscle forces exerted during movements. Clin Biomech 22(2):131-154

Farfan H (1973) Mechanical disorders of the low back. Lea \& Febiger, Philadelphia

Fujii R, Sakaura H, Mukai Y, Hosono N, Ishii T, Iwasaki M, Yoshikawa H, Sugamoto K (2007) Kinematics of the lumbar spine in trunk rotation: In vivo three-dimensional analysis using magnetic resonance imaging. Eur Spine J 16(11):1867-1874

Garner B, Pandy M (2003) Estimation of musculotendon properties in the human upper limb. Ann Biomed Eng 31(2):207-220

Gilad I, Nissan M (1986) A study of vertebra and disc geometric relations of the human cervical and lumbar spine. Spine 11(2):154157

Granata KP (2006) Response to Static and dynamic stability of the spine. J Biomech 39:2921-2922

Gray H (1980) Gray's anatomy. 36. Warwick and Williams, London

Han J, Ahn J, Goel VK, Takeuchi R, McGowan D (1992) CT-based geometric data of human spine musculature. Part I. Japanese patients with chronic low back pain. J Spinal Disord 5(4):448-458

Hansen L, de Zee M, Rasmussen J, Andersen TB, Wong C, Simonsen EB (2006) Anatomy and biomechanics of the back muscles in the lumbar spine with reference to biomechanical modeling. Spine 31(17): 1888-1899

Hill AV (1938) The heat of shortening and the dynamic constants of muscle. Proc R Soc Lond B Biol Sci 126(843):136-195

Holzbaur KRS, Murray WM, Delp SL (2005) A model of the upper extremity for simulating musculoskeletal surgery and ana- lyzing neuromuscular control. Ann Biomed Eng 33:829-840. doi:10.1007/s10439-005-3320-7

Hultman G, Nordin M, Saraste H, Ohlsèn H (1993) Body composition, endurance, strength, cross-sectional area, and density of mm erector spinae in men with and without low back pain. J Spinal Disord 6(2):114-123

Huynh K, Gibson I, Lu W, Jagdish B (2010) Simulating dynamics of thoracolumbar spine derived from LifeMOD under haptic forces. World Acad Sci Eng Technol 64:278-285

Ikai M, Fukunaga T (1968) Calculation of muscle strength per unit cross-sectional area of human muscle by means of ultrasonic measurement. Eur Appl Physiol Occupational Physiol 26(1):2632

Jorgensen M, Marras W, Granata K, Wiand J (2001) MRI-derived moment-arms of the female and male spine loading muscles. Clin Biomech 16(3):182-193

Jorgensen MJ, Marras WS, Gupta P, Waters TR (2003) Effect of torso flexion on the lumbar torso extensor muscle sagittal plane moment arms. Spine J 3(5):363-369

Kozanek M, Wang S, Passias PG, Xia Q, Li G, Bono CM, Wood K, Li G (2009) Range of motion and orientation of the lumbar facet joints in vivo. Spine 34(19):E689-E696

Lambrecht JM, Audu ML, Triolo RJ, Kirsch RF (2009) Musculoskeletal model of trunk and hips for development of seated-posturecontrol neuroprosthesis. J Rehabil Res Dev 46(4):515-528

Lee W-E, Uhm H-W, Nam Y-S (2008) Estimation of tendon slack length of knee extension/flexion muscle. In: Proceedings of the international conference on control, automation and systems (ICCAS 2008). COEX, Seoul, pp 1-4

Li G, Wang S, Passias P, Xia Q, Li G, Wood K (2009) Segmental in vivo vertebral motion during functional human lumbar spine activities. Eur Spine J 18(7):1013-1021

Lichtwark G, Wilson A (2008) Optimal muscle fascicle length and tendon stiffness for maximising gastrocnemius efficiency during human walking and running. J Theor Biol 252(4):662-673

Lieber RL, Loren GJ, Fridén J (1994) In vivo measurement of human wrist extensor muscle sarcomere length changes. J Neurophysiology 71:874-881

Lonnemann ME, Paris SV, Gorniak GC (2008) A morphological comparison of the human lumbar multifidus by chemical dissection. J Man Manipulative Ther 16(4):E84-E92

Macintosh JE, Bogduk N (1986) The biomechanics of the lumbar multifidus. Clin Biomech 1:205-213

Macintosh JE, Bogduk N (1987) 1987 Volvo award in basic science. The morphology of the lumbar erector spinae. Spine 12(7):658 668

Macintosh JE, Bogduk N (1991) The attachments of the lumbar erector spinae. Spine 16(7):783-792

Macintosh JE, Bogduk N, Pearcy MJ (1993) The effects of flexion on the geometry and actions of the lumbar erector spinae. Spine 18(7):884

Manal K, Buchanan T (2004) Subject-specific estimates of tendon slack length: a numerical method. J Appl Biomech 20:195-203

Marras W, Jorgensen M, Granata KP, Wiand B (2001) Female and male trunk geometry: size and prediction of the spine loading trunk muscles derived from MRI. Clin Biomech 16(1):38-46

McGill S (1996) A revised anatomical model of the abdominal musculature for torso flexion efforts. J Biomech 29(7):973-977

McGill S, Childs A, Liebenson C (1999) Endurance times for low back stabilization exercises: Clinical targets for testing and training from a normal database. Arch Phys Med Rehabil 80(8):941-944

McGill S, Hughson R, Parks K (2000) Changes in lumbar lordosis modify the role of the extensor muscles. Clin Biomech 15(10):777780

McGill S, Juker D, Kropf P (1996a) Appropriately placed surface EMG electrodes reflect deep muscle activity (psoas, quadratus 
lumborum, abdominal wall) in the lumbar spine. $\mathrm{J}$ Biomech 29(11):1503-1507

McGill S, Juker D, Kropf P (1996b) Quantitative intramuscular myoelectric activity of quadratus lumborum during a wide variety of tasks. Clin Biomech 11(3):170-172

McGill S, Norman R (1987) Effects of an anatomically detailed erector spinae model on L4/L5 disc compression and shear. J Biomech 20(6):591-600

Meakin J, Gregory J, Smith F, Gilbert F, Aspden R (2008) Characterizing the shape of the lumbar spine using an active shape model: reliability and precision of the method. Spine 33(7):807-813

Metzger MF, Faruk Senan NA, O'Reilly OM (2010) On cartesian stiffness matrices in rigid body dynamics: An energetic perspective. Multibody Syst Dyn 24(4):441-472. doi:10.1007/ s11044-010-9205-z

Monteiro NMB, daSilva MPT, Folgado JOMG, Melancia JPL (2011) Structural analysis of the intervertebral discs adjacent to an interbody fusion using multibody dynamics and finite element cosimulation. Multibody Syst Dyn 25:245-270. doi:10.1007/ s11044-010-9226-7

Moseley L, Hodges PW, Gandevia SC (2003) External perturbation of the trunk in standing humans differentially activates components of the medial back muscles. J Physiol 547(2):581-587. doi:10. 1113/jphysiol.2002.024950

Nachemson A (1966) Electromyographic studies on the vertebral portion of the psoas muscle: With special reference to its stabilizing function of the lumbar spine. Acta Orthop 37(2):177-190

Nachemson A (1968) The possible importance of the psoas muscle for stabilization of the lumbar spine. Acta Orthop 39(1-3):47-57

Nissan M, Gilad I (1986) Dimensions of human lumbar vertebrae in the sagittal plane. J Biomech 19(9):753-758

Ochia RS, Inoue N, Renner SM, Lorenz EP, Lim T-H, Andersson GBJ, An HS (2006) Three-dimensional in vivo measurement of lumbar spine segmental motion. Spine 31(18):2073-2078

O’Reilly OM, Metzger MF, Buckley JM, Moody DA, Lotz JC (2009) On the stiffness matrix of the intervertebral joint: Application to total disk replacement. J Biomech Eng 131(8):081007-1-081007-9

Pandy MG (1999) Moment arm of a muscle force. Exerc Sport Sci Rev 27:79-118

Panjabi MM, Brand RA, White AA (1976) Three-dimensional flexibility and stiffness properties of the human thoracic spine. J Biomech 9(4):185-192

Panjabi MM, Goel VK, Oxland T, Takata K, Duranceau J, Krag M, Price M (1992) Human lumbar vertebrae: quantitative threedimensional anatomy. Spine 17(3):299-306

Pearcy MJ, Bogduk N (1988) Instantaneous axes of rotation of the lumbar intervertebral joints. Spine 13(9):1033-1041

Pearcy MJ, Tibrewal S (1984) Axial rotation and lateral bending in the normal lumbar spine measured by three-dimensional radiography. Spine 9(6):582-587

Pearsall DJ, Reid J, Livingston L (1996) Segmental inertial parameters of the human trunk as determined from computed tomography. Ann Biomed Eng 24(2):198-210

Pearsall DJ, Reid J, Ross R (1994) Inertial properties of the human trunk of males determined from magnetic resonance imaging. Ann Biomed Eng 22(6):692-706

Phillips S, Mercer S, Bogduk N (2008) Anatomy and biomechanics of quadratus lumborum. Proc Inst Mech Eng H J Eng Med 222(2):151-159

Ramsay JW, Hunter BV, Gonzalez RV (2009) Muscle moment arm and normalized moment contributions as reference data for musculoskeletal elbow and wrist joint models. J Biomech 42(4):463-473. doi:10.1016/j.jbiomech.2008.11.035
Rosatelli A, Ravichandiran K, Agur A (2008) Three-dimensional study of the musculotendinous architecture of lumbar multifidus and its functional implications. Clin Anat 21(6):539-546

Rozumalski A, Schwartz MH, Wervey R, Swanson A, Dykes DC, Novacheck T (2008) The in vivo three-dimensional motion of the human lumbar spine during gait. Gait Posture 28(3):378-384

Santaguida P, McGill S (1995) The psoas major muscle: a three-dimensional geometric study. J Biomech 28(3):339-345

Schultz AB, Andersson GBJ (1981) Analysis of loads on the lumbar spine. Spine 6(1):76-82

Shirazi-Adl A. (1991) Finite-element evaluation of contact loads on facets of an L2-L3 lumbar segment in complex loads. Spine 16(5):533-541

Stokes IAF, Gardner-Morse MG (1995) Lumbar spine maximum efforts and muscle recruitment patterns predicted by a model with multijoint muscles and joints with stiffness. J Biomech 28(2):173186

Stokes IAF, Gardner-Morse MG (1999) Quantitative anatomy of the lumbar musculature. J Biomech 32(3):311-316

Stokes IAF, Gardner-Morse MG, Churchill D, Laible JP (2002) Measurement of a spinal motion segment stiffness matrix. J Biomech 35(4):517-521

Stokes IAF, Gardner-Morse MG, Henry SM (2010) Intra-abdominal pressure and abdominal wall muscular function: spinal unloading mechanism. Clin Biomech 25(9):859-866

Thelen DG (2003) Adjustment of muscle mechanics model parameters to simulate dynamic contractions in older adults. J Biomech Eng 125:70-77

Troke M, Moore AP, Maillardet FJ, Hough A, Cheek E (2001) A new, comprehensive normative database of lumbar spine ranges of motion. Clin Rehabil 15(4):371-379

van Dieen J, Kingma I (1999) Total trunk muscle force and spinal compression are lower in asymmetric moments as compared to pure extension moments. J Biomech 32(7):681-687

Vasavada AN, Li S, Delp SL (1998) Influence of muscle morphometry and moment arms on the moment-generating capacity of human neck muscles. Spine 23(4):412-422

Walker SM, Schrodt G (1974) I segment lengths and thin filament periods in skeletal muscle fibers of the rhesus monkey and the human. Anatomical Record 178(1):63-81

Ward SR, Eng CM, Smallwood LH, Lieber RL (2009a) Are current measurements of lower extremity muscle architecture accurate. Clin Orthop Relat Res 467(4):1074-1082

Ward SR, Kim CW, Eng CM, Gottschalk LJ, Tomiya A, Garfin SR, Lieber RL (2009b) Architectural analysis and intraoperative measurements demonstrate the unique design of the multifidus muscle for lumbar spine stability. J Bone Joint Surg 91(1):176-185

Ward SR, Tomiya A, Regev GJ, Thacker BE, Benzl RC, Kim CW, Lieber RL (2009c) Passive mechanical properties of the lumbar multifidus muscle support its role as a stabilizer. J Biomech 42(10):1384-1389

Weis-Fogh T, Alexander MN (1977) The sustained power output from striated muscle. In: Pedley TJ (ed) Scale effects in animal locomotion. Academic Pess, London

White AA, Panjabi MM (1978a) The basic kinematics of the human spine. a review of past and current knowledge. Spine 3(1):12-20

White AA, Panjabi MM (1978b) Clinical biomechanics of the spine. Lippincott, Philadelphia

Wilkenfeld A, Audu M, Triolo RJ (2006) Feasibility of functional electrical stimulation for control of seated posture after spinal cord injury: a simulation study. J Rehabil Res Develop 43(2):139152

Woltring HJ, Huiskes R, deLange A, Veldpaus FE (1985) Finite centroid and helical axis estimation from noisy landmark measurements in 
the study of human joint kinematics. J Biomech 18(5):379-389. doi:10.1016/0021-9290(85)90293-3

Wong K, Luk K, Leong J, Wong S, Wong K (2006) Continuous dynamic spinal motion analysis. Spine 31(4):414-419

Xiao M, Higginson J (2010) Sensitivity of estimated muscle force in forward simulation of normal walking. J Appl Biomech 2(26):142-149
Zajac FE (1989) Muscle and tendon: properties, models, scaling, and application to biomechanics and motor control. Crit Rev Biomed Eng 17(4):359-411 